\title{
A Novel Excitation Approach to Ultrasonically-Assisted Cylindrical Grinding
}

\author{
Vytautas Ostaševičius ${ }^{1}$ - Vytautas Jūrẻnas ${ }^{1}$ - Andrius Vilkauskas ${ }^{1}$ - Gytautas Balevičius ${ }^{1, *}$ \\ - Andrius Senkus ${ }^{2}$ - Eglè Jotautiené ${ }^{2}$ \\ ${ }^{1}$ Kaunas University of Technology, Institute of Mechatronics, Lithuania \\ 2 Aleksandras Stulginskis University, Institute of Agricultural Engineering and Safety, Lithuania
}

\begin{abstract}
Usage of ultrasound is prevalent in a wide range of industrial applications; it is employed in aiding the removal of hard-to-machine materials. In such cases, special care needs to be taken in designing an ultrasonic horn, as the geometrical make-up of this part that strongly influences the ultrasonic power output, frequency, and amplitude transferred to the area of effect. This article proposes a novel solution to the excitation of rotating interfaces: the excitation of the workpiece in cylindrical grinding. The approach focuses on the excitation of stationary centres, holding the workpiece, rather than the workpiece itself. The modelling and development procedures for a high-power actuator as well as experimental verifications to the validity and effectiveness of the approach are provided.
\end{abstract}

Keywords: ultrasonic horn, cylindrical grinding, finite element method, vibration assisted machining, external excitation, rotating interface excitation

\author{
Highlights \\ - A design for a robust approach to excitation of rotating parts is proposed. \\ - Appropriate dimensions of proposed actuator design are determined with FEM and parametric sweep. \\ - The effectiveness of the approach is observed through surface roughness improvements, from experimental runs.
}

\section{INTRODUCTION}

The rapid emergence and advancement of hybrid manufacturing processes (HMP) can be considered the industry's direct response to the growing need for technologies employing hard-to machine-materials (ceramics, glass, etc.). As described in [1], HMP are controlled applications of simultaneously interacting machining mechanisms that are of high relevance to the process. The main goal of HMP is to achieve what Schuh et al. [2] refer to as the " $1+1=3$ " synergy effect on the overall machining process. This effect implies not only the supplementation among the interacting machining mechanisms but also the robustness of the approach in relation to the application costs and constraints (modification of the existing machines, number of additional modules required etc.).

Vibration-assisted machining (VAM) methods are a highly researched and developed group of HMP. The basic principle of VAM employs a conventional machining process (drilling, turning, grinding, etc.) and supplements it with vibrational excitation of either the tool, the workpiece, or both. A sizeable amount of research has been conducted, covering different VAM processes. Graževičiūtẻ et al. [3] using a specifically designed cutting tool, supplemented with an ultrasonic actuator, observed improvements in the surface quality during turning. Ostaševičius et al. [4] developed a finite element model of a vibrating milling tool and demonstrated that high-frequency vibrations superimposed onto the continuous movement of the tool lead to milling process stabilization with superior surface finish in comparison to conventional machining. Ultrasonically assisted dry grinding (UADG) has been employed by Tawakoli and Azarhoushang [5] to compensate for low material removal rates, poor surface quality, and other issues prevalent in the conventional dry grinding (CDG), due to lack of coolant. Ultrasonic vibration was found to be effective in aiding the grinding of difficult to cut materials (titanium, ceramics, etc.); researchers attributed it to the reduction of temperature and tool wear due to longitudinal vibration [6]. The use of vibration for grinding is more prevalent in grinding on a machine with a vertical grinding spindle [7], as longitudinal vibration is considered to provide the highest penetration power. However, it is possible to transform longitudinal vibrations into transverse modes for horizontal processes, such as turning or cylindrical grinding. In these processes, the workpiece would need to be excited in the transverse mode. Workpiece excitation holds great promise, as demonstrated by Liang et al. [8] in their ultrasonically assisted grinding of monocrystalline silicon.

The application of vibrational excitation to static parts (lathe tool, statically mounted workpiece, etc.) is rather straightforward. The modifications limit themselves to the mounting of an actuator to the said 
part. The application to moving parts (rotating tools and workpieces), however, is more complex, as it requires additional modules to be put in place to drive and control the actuators situated on the moving part.

The authors of this paper propose a novel, robust alternative for rotating component excitation that has the potential to be applied to any process involving a rotating tool or workpiece. Instead of mounting the actuator on the rotating interface, it is to be mounted immediately outside it, either through a collar or bracket link, thus eliminating the need for additional modules. Such an approach, to the best of the authors' knowledge, has not previously been applied.

This article aims to develop and test a prototype of the proposed approach. The main challenge is the development of an actuator that possesses reasonable power requirements, yet remains able to transfer the vibration between the moving and static interfaces. Therefore, this article, firstly, concerns itself with the behaviour of the excitation target; modelling, development, and testing of the actuator follow immediately afterward.

Overall representation of the research flow, can be found in Fig. A1 (Appendix A).

\section{DEVELOPMENT OF THE EXCITATION SET-UP}

To maintain a sufficient level of control during the initial testing stages, a process with a relatively slowly rotating part had to be chosen. Such a part can be recognized as the workpiece in the cylindrical surface grinding process. When considering the specific setup for the Supertec G32P-100NC grinding machine (Fig. 1), it can be seen that the actuator (1) can be mounted via a clamp collar (2) onto the sleeve of the tailstock (3); in the initial analysis stages, interaction between the workpiece (4) and tool (5) is ignored. Two workpieces (a uniform and a stepped shaft) are used in experiments.

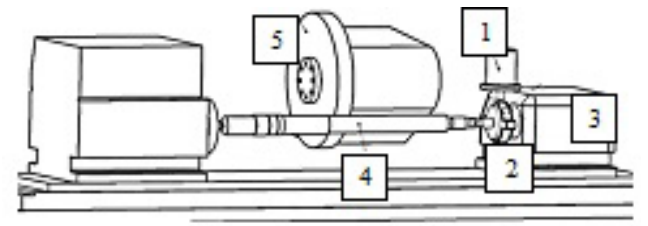

Fig. 1. Excitation set-up for Supertec G32P-100NC grinding machine: 1) actuator; 2) clamp collar; 3) tail stock; 4) workpiece; 5) tool

The studies concerning the workpiece behaviour are aimed at determining the most suitable excitation frequencies and required excitation force. These studies are tackled first, since their results serve as inputs for further study and development of the actuator. The actuator development requires the derivation and adjustment of ultrasonic horn dimensions, to suit the operation to workpiece frequency. Upon completion of the design, the viability of the excitation approach is tested by determining the power requirements for producing expected workpiece excitation amplitudes.

\subsection{Dynamic Behaviour of the Workpiece}

Before studying the behaviour of the workpiece any further, a set of target conditions is set forth: 1 . Since the tool approaches perpendicularly to the workpiece axis, the latter should vibrate in a transverse mode; 2. The frequency of excitation must not be lower than $15 \mathrm{kHz}$, as lower values would be too far from the ultrasonic threshold; 3. The target amplitude of excitation needs to be above $1 \mu \mathrm{m}$, as most encountered applications tend to employ amplitudes of such orders of magnitude. The first two conditions can be tackled by employing modal analysis.

If the law of motion of the excited end of the workpiece is to be considered known and defined by a nodal displacement vector $\mathbf{U}_{K}$, the block form of the equation of motion (EOM) of the workpiece is written as Eq. (1):

$$
\left[\begin{array}{ll}
\mathbf{M}_{N N} & \mathbf{M}_{N K} \\
\mathbf{M}_{K N} & \mathbf{M}_{K K}
\end{array}\right]\left\{\begin{array}{c}
\ddot{\mathbf{U}}_{N} \\
\ddot{\mathbf{U}}_{K}
\end{array}\right\}+\left[\begin{array}{ll}
\mathbf{K}_{N N} & \mathbf{K}_{N K} \\
\mathbf{K}_{K N} & \mathbf{K}_{K K}
\end{array}\right]\left\{\begin{array}{c}
\mathbf{U}_{N} \\
\mathbf{U}_{K}
\end{array}\right\}=\left\{\begin{array}{c}
0 \\
\mathbf{R}
\end{array}\right\} .
$$

Here, $N$ and $K$ are indices representing nodes whose displacements are unknown (free nodes) and known (excited or constrained nodes), respectively. Hence, $\mathbf{U}_{N}$ and $\mathbf{U}_{K}$ are nodal displacement vectors for free and constrained vectors, respectively, while pair combinations of these indices relay the position of these nodes in respective property matrices $\mathbf{M}$ (mass matrix) and $\mathbf{K}$ (stiffness matrix). Additionally, $\mathbf{R}$ is the vector of unknown reaction forces of nodes under excitation.

Modal analysis of an undamped oscillatory motion finds resonant frequencies by solving the following Eq. (2), where, $\omega$ is the angular frequency, while $\hat{\mathbf{U}}$ is the mode shapes vector.

$$
\left(\mathbf{K}-\omega^{2} \mathbf{M}\right) \widehat{\mathbf{U}}=\{0\} .
$$

The modal analysis of the workpieces is performed employing the modal analysis module of ANSYS Workbench software. ANSYS Workbench suite uses Block Lanczos extraction method to obtain the vibration modes in prescribed frequency ranges. 
Knowledge of appropriate frequencies of the workpieces allows application of a periodic forcing condition at the tailstock mount (Fig. 2). Transverse deformation amplitudes can be observed as a result, and the most suitable force value and frequency can be determined. In ANSYS Workbench, the harmonic response module can be used for this purpose.

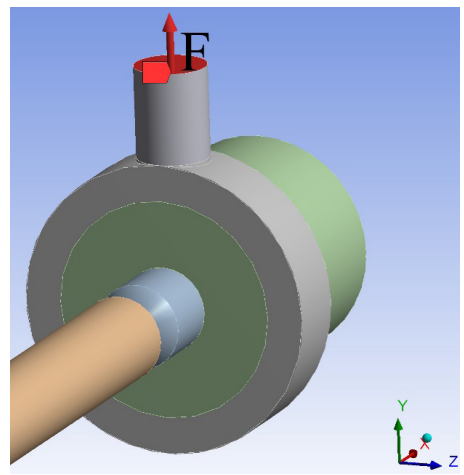

Fig. 2. Excitation force $F$ application at the tailstock attachment

In the case of the two workpieces, both are constrained at the tailstock end and pre-stressed by the headstock. The mode search is performed between 15 $\mathrm{kHz}$ and $25 \mathrm{kHz}$; the resulting mode frequencies are then used to define the excitation of the workpiece at an arbitrary magnitude of $1 \mathrm{~N}$.

The choice of the most suitable frequency has been simplified to fit the three criteria in descending order of importance: 1. neighbourhood of the frequency needs to be clear of other modes; 2 . the average peakto-peak, workpiece displacement value (an average of absolute values of oscillation amplitudes across the length of the workpiece) needs to be relatively high; 3. the mode frequency is in close proximity to similar mode frequencies in the other workpiece. To better illustrate the choice of the frequency, scatter plots are presented in Appendix B (Figs. B1 to 4). As a result, excitation frequencies at around $15.8 \mathrm{kHz}$ have been chosen for both workpieces.

Carrying out a parametric sweep of the excitation force yields an average deformation amplitude of 1.5 $\mu \mathrm{m}$ at $2.1 \mathrm{~N}$ (Appendix C Figs. C1 and 2). Hence, the actuator will have to be able to be driven at $15.85 \mathrm{kHz}$ and $15.794 \mathrm{kHz}$, and will need to produce a reaction force of $2.1 \mathrm{~N}$ at the fixture.

\subsection{Development of the Ultrasonic Actuator}

The initial design of the actuator is based on preexisting dimensional and material requirements, as well as wavelength considerations. The actuator is to be mounted on an M30 thread at the output end of the horn; thus, the variation of the output end diameter is limited (for safety, the wall thickness is chosen as $4 \mathrm{~mm}$, resulting in minimum output end diameter of $38 \mathrm{~mm})$. The piezoelectric stack consists of two piezo ceramic rings of dimensions $80 \mathrm{~mm} \times 30 \mathrm{~mm} \times 12 \mathrm{~mm}$. This, in turn, defines the diameter of the input end of the horn and the backing mass to be $80 \mathrm{~mm}$. For safe operation, the actuator is to be encased in a protective housing, which is mounted on an additionally formed flange, it is relatively light however and therefore will be neglected in further studies. To determine the lengths of the horn and the back mass, it is necessary to first define their materials.

A common guideline when choosing the material is to match the characteristic impedances of the piezo stack and front-back masses accordingly [9]:

$$
z_{c}=\sqrt{z_{f} z_{b}} .
$$

Here $z_{c}, z_{f}$, and $z_{b}$ are characteristic impedances of centre stack, front mass and back mass respectively. After reviewing available material data and obtaining impedance values, a decision was made to manufacture the front mass from tool steel and back mass from an aluminium alloy. Bearing this in mind longitudinal dimensions of the actuator can be further considered.

The shape of the front mass is also an important factor in the transfer of ultrasonic energy to the output end of the actuator. Nad [10] and Nguyen and Wang [11] extensively researched the dynamic properties of different geometric shapes. However, since not much variation is allowed due to lateral dimension constraints, an exponential shape profile is considered, based on work by Al-Budairi [12].

The entire actuator is expected to oscillate at a half wave length; here, horn covers the first quarter of the wavelength, while the other quarter is in the centre stack and back mass. The wavelength for each material can be calculated using the following formula:

$$
\lambda=\frac{c}{f} .
$$

Here, $c$ is the sound velocity in the medium, while $f$ is the excitation frequency. The sound velocity can be determined accordingly:

$$
c=\sqrt{\frac{E}{\rho}},
$$

where $E$ is Young's modulus, and $\rho$ is the density of the material. Wavelength values can be found in Table 1. 
Table 1. Material properties and physical dimensions

\begin{tabular}{|l|c|c|c|}
\hline & Tool steel & PZT & Aluminium \\
\hline Young's modulus [GPa] & 170 & 73 & 78 \\
\hline Density [g cm-3 ${ }^{3}$ & 7.700 & 7.600 & 2.850 \\
\hline Sound velocity [m s-1] & 4698.715 & 3099.236 & 5231.484 \\
\hline Wavelength [m] & 0.297 & 0.196 & 0.330 \\
\hline Length [m] & 0.074 & 0.025 & 0.041 \\
\hline
\end{tabular}

With all the data obtained, the derivation of front mass length is straight forward: one quarter of the wavelength for the tool steel. Since the value of the centre stack length was already known, it was determined to take up an eighth of its wavelength, making it possible to derive the back-mass value: an eighth of the wavelength for the aluminium alloy. These values were used in the initial design for modal analysis (Fig. 3). Here, a longitudinal mode was expected to occur at $15.794 \mathrm{kHz}$. However, mode search at 15 $\mathrm{kHz}$ to $25 \mathrm{kHz}$ yielded frequency values $2 \mathrm{kHz}$ above this value. A parametric sweep of the horn length was conducted and a longitudinal mode was observed at $15.939 \mathrm{kHz}$ when the horn length was $111 \mathrm{~mm}$.

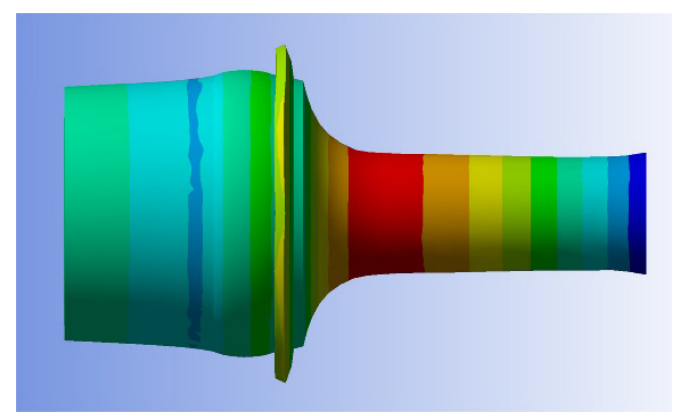

Fig. 3. Longitudinal mode of the initial actuator design

The newly designed actuator was tested in a harmonic response study; here, both planar faces of the piezo stack were assigned arbitrary forces of the opposite sign, to simulate excitation from the piezostack. The force at the output end of the horn was measured, allowing the performance of a parametric sweep to determine the required input force, to produce $2.1 \mathrm{~N}$ at $15.794 \mathrm{kHz}$ and $15.850 \mathrm{kHz}$ on the output end, as required for excitation of the uniform cylinder and stepped shaft to $1.5 \mu \mathrm{m}$, respectively. The required input force was determined to be $19 \mathrm{~N}$ and 20 $\mathrm{N}$ for $15.794 \mathrm{kHz}$ and $15.850 \mathrm{kHz}$ cases respectively (Fig. 4).

Knowing the required force and velocity of vibration, allows determining the power requirements:

$$
P=F v \cos \varphi \text {. }
$$

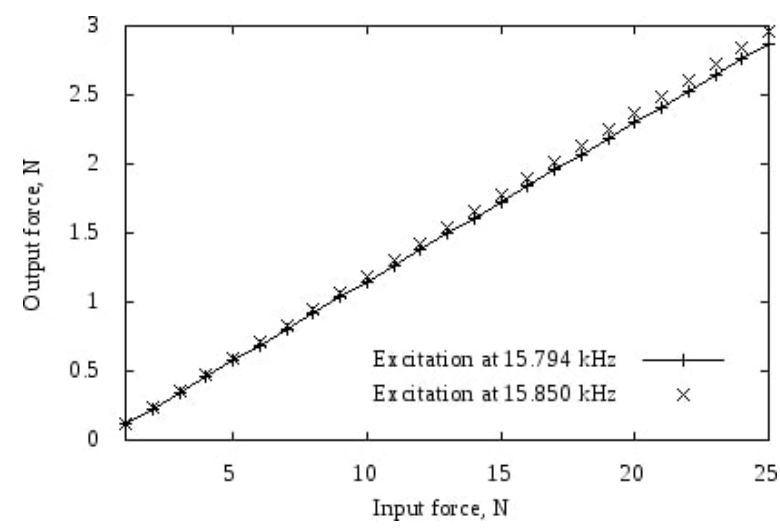

Fig. 4. Input-output force dependency for actuator at $15.794 \mathrm{kHz}$ and $15.850 \mathrm{kHz}$

Here $\varphi$ is considered to be the phase difference between the velocity and force. The obtained result shows the required power input of the transducer required to achieve force $F$ during excitation. Since accelerations at the piezo-material to front-mass interface were determined to be $2070 \mathrm{~mm} / \mathrm{s}^{2}$ and $2000 \mathrm{~mm} / \mathrm{s}^{2}$ for $15.794 \mathrm{kHz}$ and $15.850 \mathrm{kHz}$ cases, respectively, peak velocities in both cases were found to be $20 \mathrm{~mm} / \mathrm{s}$. Assuming force and velocity to be in phase, Eq. (6) yields the following values:

$$
\begin{aligned}
& P_{15.794}=F v \cos \varphi=19 \times 20=380 \mathrm{~W}, \\
& P_{15.855}=F v \cos \varphi=20 \times 20=400 \mathrm{~W} .
\end{aligned}
$$

This demonstrates that the approach requires realistic power values and is theoretically feasible. Further investigations of the fully assembled system are necessary.

\section{EXCITATION SYSTEM VERIFICATION}

With working modes determined and the design of the actuator verified, a fully assembled system needs to be tested. Initial tests are performed using harmonic analysis in ANSYS workbench: here the displacement of the workpiece in the fully assembled system when the piezo stack is excited at the predetermined force and frequency is observed. Afterwards the excitation output is tested on a physical system. Lastly the effectiveness of the approach is tested by observing surface grinding results with and without operation of the actuator.

\subsection{Harmonic Response of the Fully Assembled System}

The harmonic analysis data for both workpiece configurations is presented in Table 2. 
Table 2. Workpiece excitation parameters

\begin{tabular}{lcc}
\hline Workpiece & Excitation force $[\mathrm{N}]$ & Frequency $[\mathrm{kHz}]$ \\
\hline Uniform cylinder & 20 & 15.850 \\
\hline Stepped shaft & 19 & 15.794 \\
\hline
\end{tabular}

The workpiece displacement graphs (Figs. 5 and 6) show a noticeable reduction in amplitude.

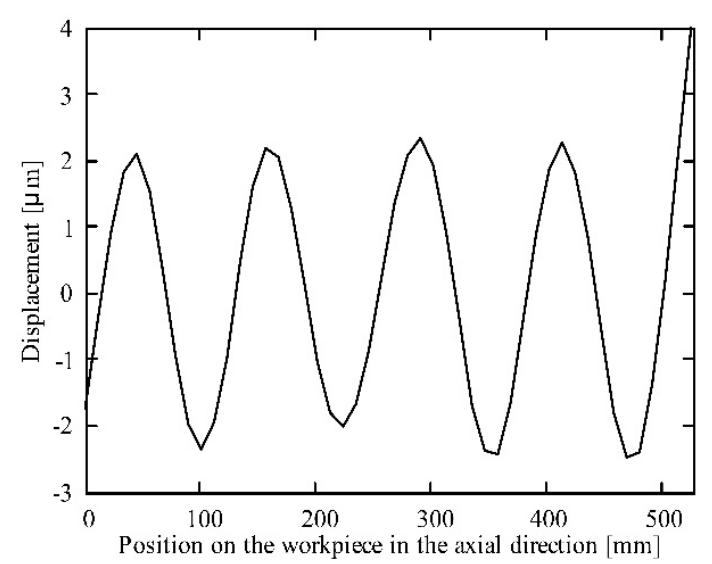

Fig. 5. Response of the uniform cylinder workpiece, being driven by $20 \mathrm{~N}$ at $15.85 \mathrm{kHz}$ frequency, with the actuator attached

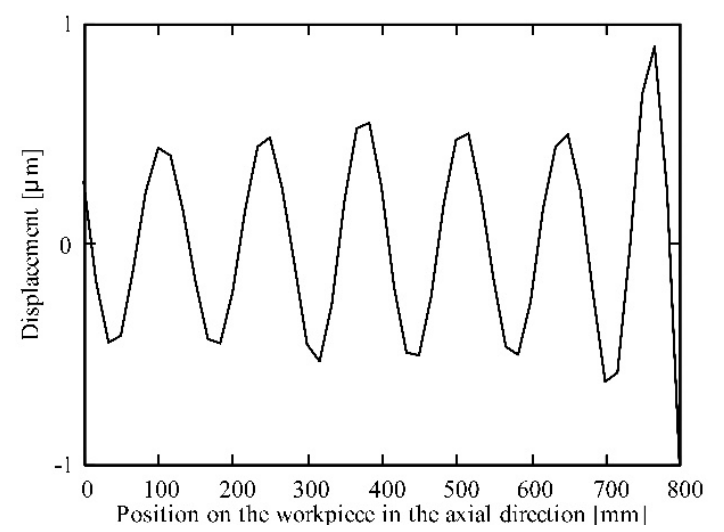

Fig. 6. Response of the stepped shaft workpiece, driven by

$20 \mathrm{~N}$ at $15.794 \mathrm{kHz}$ frequency with the actuator attached

Additional modal analysis of the entire assembly was performed, demonstrating that the addition of the actuator to the system shifted the transverse mode frequency to $17.349 \mathrm{kHz}$ and $17.722 \mathrm{kHz}$ for the uniform cylinder and stepped shaft workpieces, respectively (Figs. 7 and 8), which was the cause for the decrease in displacement.

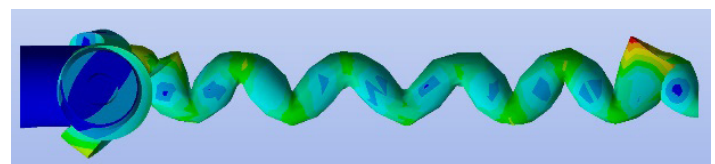

Fig. 7. Shifted transverse mode for uniform cylinder at $17.349 \mathrm{kHz}$

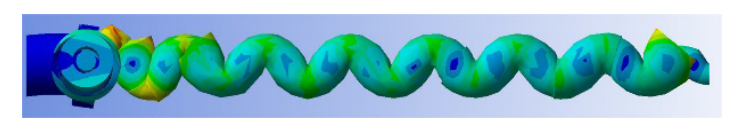

Fig. 8. Shifted transverse mode for stepped shaft at $17.722 \mathrm{kHz}$

Driving the systems at $17.349 \mathrm{kHz}$ and 17.722 $\mathrm{kHz}$ yielded more appropriate responses in the order of micrometres (Figs. 9 and 10).

Similar changes are also expected to occur in the physical system; therefore, experimental vibration analysis is essential in this case.

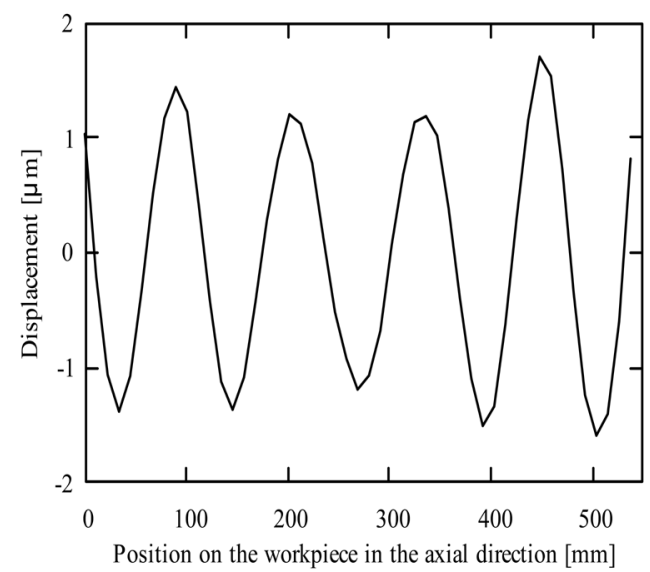

Fig. 9. Response of the uniform cylinder workpiece, driven by $19 \mathrm{~N}$ at $17.349 \mathrm{kHz}$ frequency, with the actuator attached

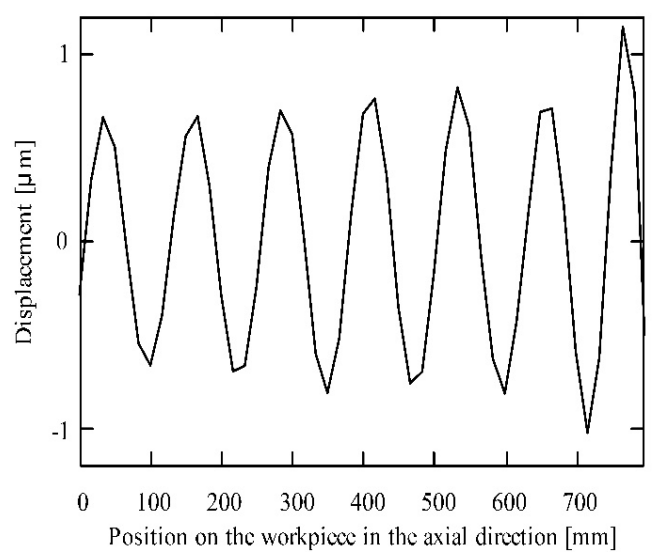

Fig. 10. Response of the stepped shaft workpiece, driven by $19 \mathrm{~N}$ at $17.722 \mathrm{kHz}$ frequency with the actuator attached

\subsection{Physical Excitation Measurements}

The physical system consists of a Supertec G32D $100 \mathrm{NC}$ cylindrical grinding machine with the actuator mounted at the tailstock. The actuator is driven by a Sensotronica BT400 ultrasonic generator; from the tailstock, the oscillations are expected to be transferred to the workpiece at $17.349 \mathrm{kHz}$ for a 
uniform cylinder workpiece and $17.722 \mathrm{kHz}$ for a stepped shaft workpiece.

For measurement, a PicoScope 3424 oscilloscope with a KD-91 accelerometer is used. With the ultrasonic generator at $40 \%$ power, amplitudes of $0.368 \mu \mathrm{m}$ were observed to occur at $16.818 \mathrm{kHz}$ for both workpieces. The acceleration (Fig. 11) is in close proximity to the values obtained during simulation. This change corresponds with observations made in the previous sub-chapter, regarding the shift of mode frequency, due to the addition of the actuator. These conditions are to be further used in vibration assisted grinding (VAG) experiments.

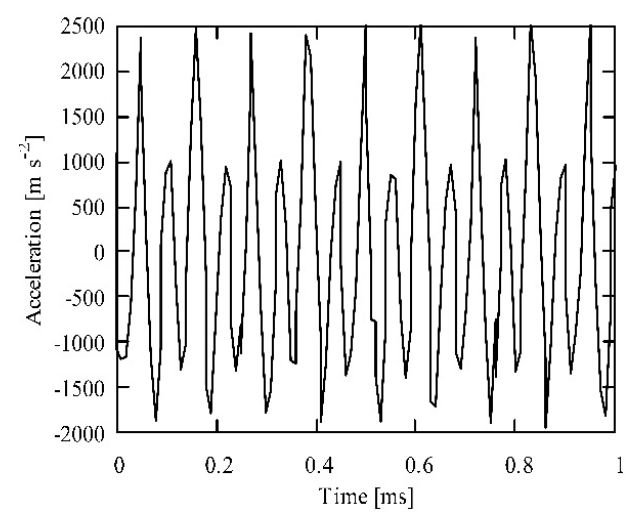

Fig. 11. Acceleration at $16.818 \mathrm{kHz}$

\subsection{Experimental Vibration-Assisted Grinding Study}

To test the effectiveness of the system, a grinding trial was conducted. After each grinding run, surface quality was measured using a Mitutoyo Surftest SJ210 surface roughness tester. Each measurement was performed 5 times, at sampling and cut-off lengths of $0.8 \mathrm{~mm}$.

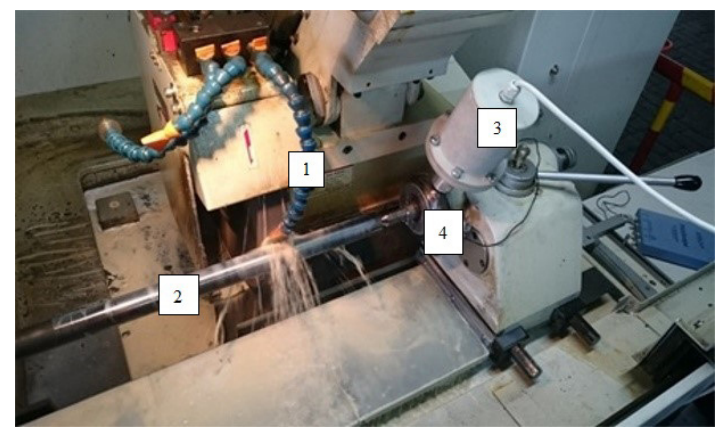

Fig. 12. Wet cylindrical grinding process : 1. Coolant nozzle; 2. Actuator; 3. Work-piece; 4. Bracket link

Experiments were carried out with and without vibrations for wet (Fig. 12) and dry grinding.
The settings of the machining parameters for the experiment are summarized in Table 3 and ultrasonically-assisted grinding zones are shown in Fig. 13.

The first experiment was carried out on a 1.1186 steel shaft using a conventional grinding method (without ultrasonic vibrations).

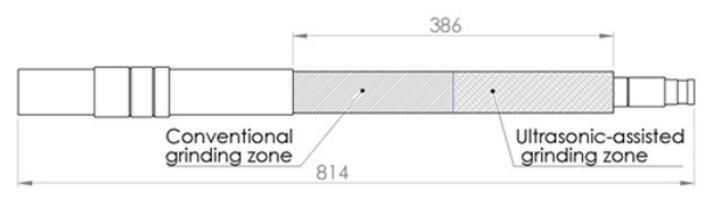

Fig. 13. Different grinding areas for stepped shaft workpiece

Table 3. Experimental set-up

\begin{tabular}{|c|c|}
\hline Grinding wheel & $\begin{array}{l}\text { Vitrified bond ZrA grinding wheel, } \\
\text { grain size } 80,405 / 210 / 50\end{array}$ \\
\hline \multirow{2}{*}{$\begin{array}{l}\text { Workpiece } 1 \\
\text { (stepped shaft) }\end{array}$} & $\begin{array}{l}1.1186 \text { medium carbon steel, } \\
\text { Vickers hardness } 280\end{array}$ \\
\hline & $(L=814 \mathrm{~mm}, \emptyset=50 \mathrm{~mm})$ \\
\hline \multirow{2}{*}{$\begin{array}{l}\text { Workpiece } 2 \\
\text { (uniform cylinder) }\end{array}$} & $\begin{array}{l}1.7225 \text { 42CrMo4, } \\
\text { Vickers hardness } 207\end{array}$ \\
\hline & $(L=500 \mathrm{~mm}, \emptyset=35 \mathrm{~mm})$ \\
\hline Grinding process & Dry/wet cylindrical grinding \\
\hline Grinding conditions & $\begin{array}{l}\text { Feed speed } v_{f}=5 \mathrm{~m} \mathrm{~min}^{-1} \\
\text { depth of cut } a_{p}=0.01 \mathrm{~mm} ; \\
\text { cutting speed } v_{c}=34 \mathrm{~m} \mathrm{~s}^{-1}\end{array}$ \\
\hline $\begin{array}{l}\text { Ultrasonic vibration } \\
\text { conditions }\end{array}$ & $\begin{array}{l}\text { Frequency } f=16818 \mathrm{~Hz} \\
\text { power } P=40 \% \\
\text { amplitude } A=0.386 \mu \mathrm{m} .\end{array}$ \\
\hline
\end{tabular}

The second experiment was carried out on a 1.7225 steel bar. The grinding zones of the experiment are shown in Fig. 14.

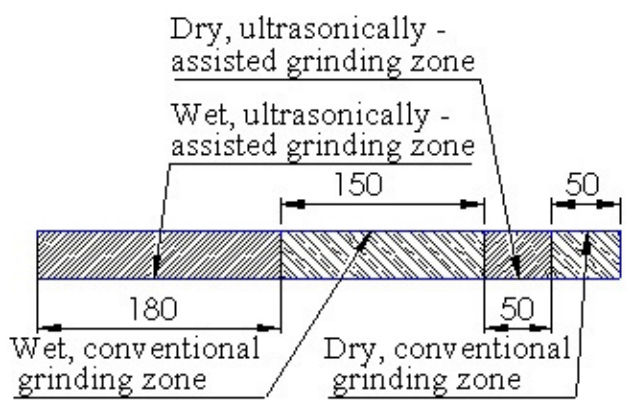

Fig. 14. Different grinding areas for uniform cylinder workpiece

After the experiments, the roughness of shaft and bar was measured with surface roughness tester at defined zones for conventional and ultrasonicallyassisted grinding with and without cooling fluid. The results of surface roughness are summarized 
in Table 4 and shown in Figs. 15 and 16. Here, UG and $\mathrm{CG}$ refer to wet grinding with ultrasound and without it, when applied to the stepped shaft, while UDG and CDG stand for ultrasonic and conventional dry grinding with UWG and CWG applied for wet grinding respectively, when dealing with the uniform steel bar.

Table 4. Surface roughness values

\begin{tabular}{lcccccc}
\hline Roughness & \multicolumn{4}{c}{1.7225 steel bar } & \multicolumn{2}{c}{1.1186 shaft } \\
\cline { 2 - 7 } $\begin{array}{l}\text { parameter } \\
{[\mu \mathrm{m}]}\end{array}$ & \multicolumn{2}{c}{ Dry grinding } & \multicolumn{2}{c}{ Wet grinding } & \multicolumn{2}{c}{ Wet grinding } \\
\cline { 2 - 7 } & UG & CG & UG & CG & UG & CG \\
\hline$R a$ & 0.442 & 0.491 & 0.418 & 0.432 & 0.251 & 0.298 \\
\hline$R q$ & 0.556 & 0.611 & 0.516 & 0.545 & 0.334 & 0.408 \\
\hline$R z$ & 3.323 & 3.315 & 2.818 & 2.843 & 2.291 & 2.939 \\
\hline
\end{tabular}

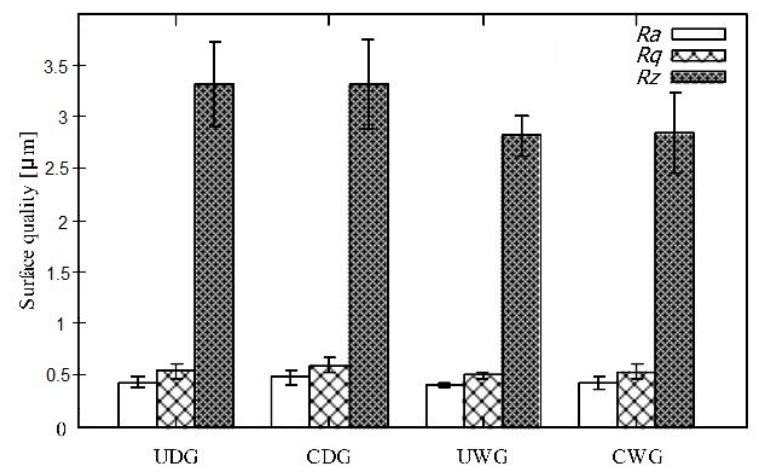

Fig. 15. Surface roughness values for grinding trials on a uniform cylinder workpiece

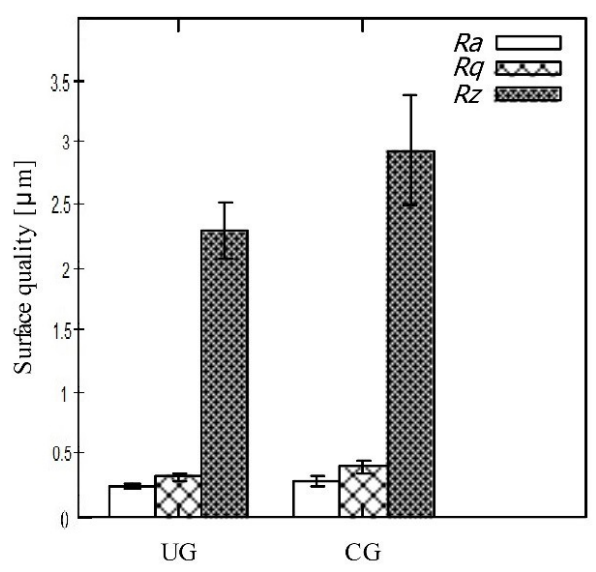

Fig. 16. Surface roughness values for grinding trials on a uniform stepped shaft workpiece

The results in the case of dry grinding are not much different between ultrasonic and conventional counterparts. Noticeable improvements were observed in ultrasonic wet grinding when compared to its conventional counterpart. This may suggest that ultrasound enables a better lubrication mechanism, improving the surface quality as a result. However, more research needs to be conducted at different amplitudes, frequencies and machining parameters.

\section{CONCLUSIONS}

This research has concluded that the application of a high-powered oscillator to the stationary support of a rotating part is a viable approach to workpiece excitation in vibration-assisted machining. In the case of this research, based on FEM calculations, a generator of $400 \mathrm{~W}$ with a transducer can produce workpiece amplitude of up to $1.5 \mu \mathrm{m}$.

Experimental investigations demonstrate the viability of the method in practice. However, the practical efficacy of the method is inconclusive, as the surface roughness test values show only a marginal improvement in the ultrasonically-assisted case.

To further contribute to this topic, upcoming research should investigate the dependence of surface roughness values on the excitation frequency and local amplitudes.

\section{ACKNOWLEDGEMENTS}

This work has been funded by EU Structural Funds project "High-level R\&D" program: measure 01.2.2-LMT-K-718.

\section{NOMENCLATURES}

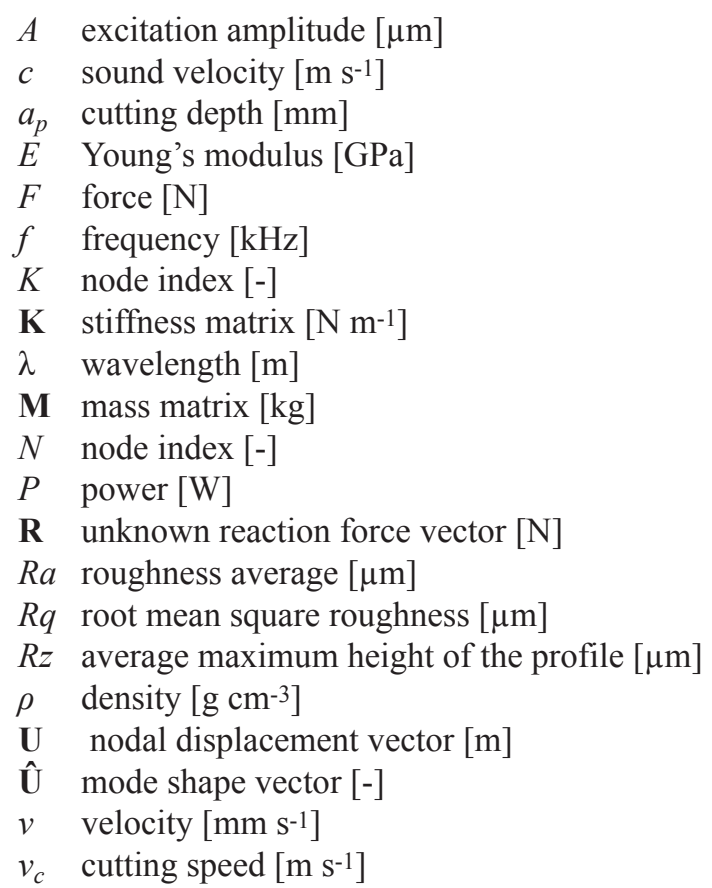


$v_{f} \quad$ feed speed [m $\left.\mathrm{min}^{-1}\right]$

$\varphi \quad$ phase angle between force and velocity [degrees]

$z_{c}, z_{f}, z_{b}$ characteristic impedances [ $\mathrm{N} \mathrm{s} \mathrm{m}^{-1}$ ]

$\omega \quad$ angular frequency [degrees s-1]

\section{REFERENCES}

[1] Lauwers, B. (2011). Surface integrity in hybrid machining processes. Procedia Engineering, vol. 19, p. 241-251, DOI:10.1016/j.proeng.2011.11.107.

[2] Schuh, G., Kreysa, J., Orilski, S. (2009). Roadmap "Hybride Produktion". Zeitschrift für Wirtschaftlichen Fabrikbetrieb, vol. 104, no. 5, p. 385-391, D0l:10.3139/104.110072.

[3] Graževičiūtè, J., Skiedraitè, I., Ostaševičius, V., Jurènas, V., Bubulis, A. (2006). Ultrasound application in turning process. Proceedings of 6th International Conference Vibroengineering, p. 152-154.

[4] Ostaševičius, V., Gaidys, R., Daukševičius, R., Mikuckytè, S. (2013). Study of vibration milling for improving surface finish of difficult-to-cut materials. Strojniški vestnik - Journal of Mechanical Engineering, vol. 59, no. 6, p. 351-357, D0I:10.5545/sv-jme.2012.856.

[5] Tawakoli, T., Azarhoushang, B. (2008). Influence of ultrasonic vibrations on dry grinding of soft steel. International Journal of Machine Tools and Manufacture, vol. 48, no. 14, p. 15851591, D0I:10.1016/j.jjmachtools.2008.05.010.
[6] Choi, Y., Park, K., Hong, Y., Kim, K., Lee, S., Choi, H. (2008). Effect of ultrasonic vibration in grinding; horn design and experiment. International Journal of Precision Engineering and Manufacturing, vol. 14, no. 11, p. 1873-1879, Dol:10.1007/ s12541-013-0253-1.

[7] Kuo, K. (2009). Ultrasonic vibrating system design and tool analysis. Transactions of Nonferrous Metals Society of China, vol. 19, suppl. 1, p. s225-s231, D0l:10.1016/S10036326(10)60275-0.

[8] Liang, Z., Wu, Y., Wang, X., Zhao, W. (2010). A new twodimensional ultrasonic assisted grinding (2D-UAG) method and its fundamental performance in monocrystal silicon machining. International Journal of Machine Tools \& Manufacture, vol. 50, no. 8, p. 728-736, Dol:10.1016/j. ijmachtools.2010.04.005.

[9] Abdullah, A., Shahini, M., Pak, A. (2009). An approach to design a high power piezoelectric ultrasonic transducer. Journal of Electroceramics, vol. 22, no. 4, p. 369-382, DOl:10.1007/s10832-007-9408-8.

[10] Nad, M. (2010). Ultrasonic horn design for ultrasonic machining technologies. Applied and Computational Mechanics, vol. 4, no. 1, p. 79-88.

[11] Nguyen, H., Wang, D. (2012). Design of an ultrasonic steel horn with a Bézier profile. International Conference on Green Technology and Sustainable Development, p. 1-9.

[12] Al-Budairi, H.D. (2012). Design and analysis of ultrasonic horns operating in longitudinal and torsional vibration. PhD thesis, University of Glasgow, Glasgow.

\section{APPENDICES}

\subsection{Appendix A}

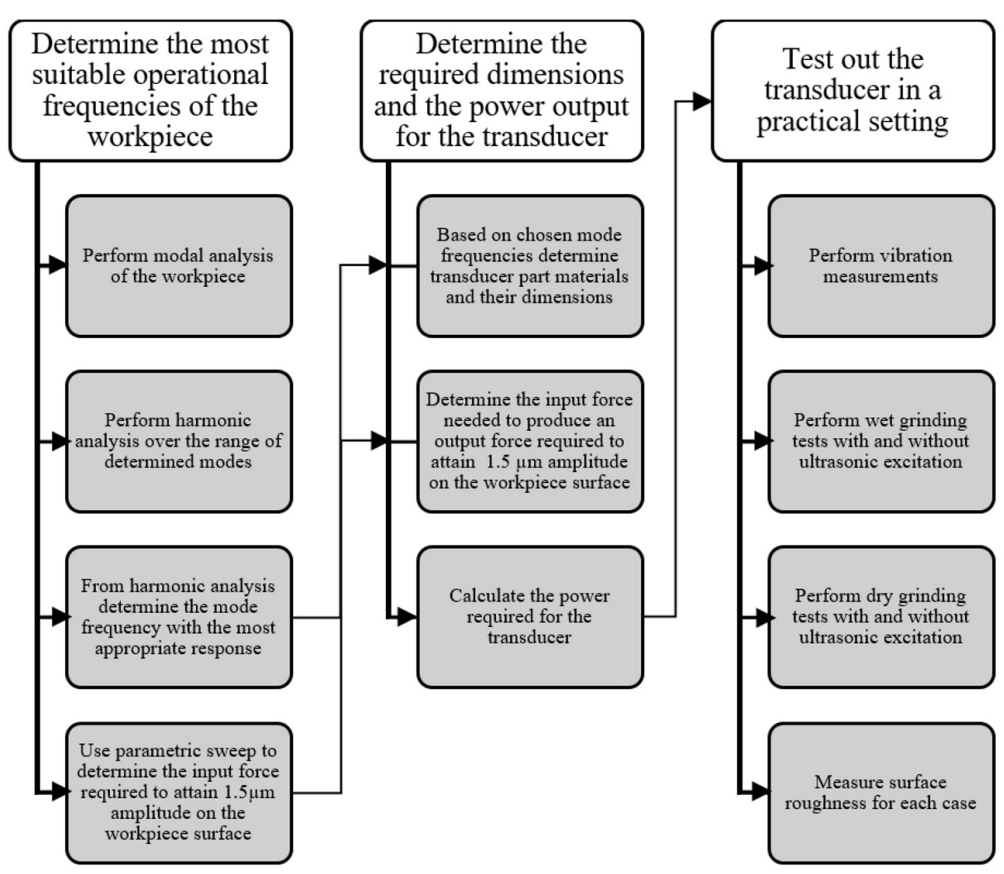

Fig. A1. Research process diagram 


\subsection{Appendix B}

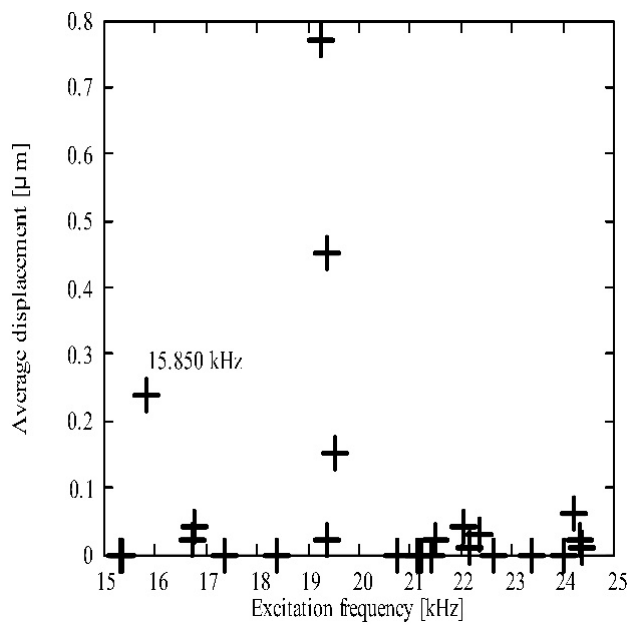

Fig. B1. Average displacement distribution based on excitation frequency ( $Y$ axis - uniform cylinder)

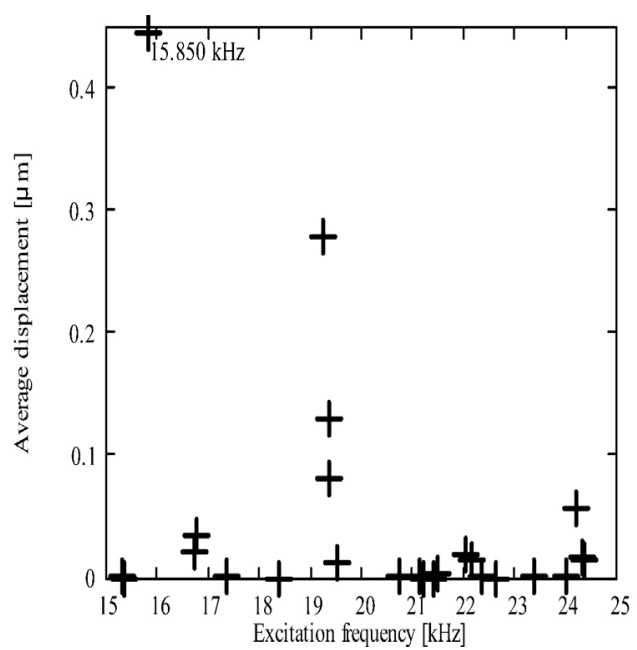

Fig. B2. Average displacement distribution based on excitation frequency ( $Z$ axis - uniform cylinder)

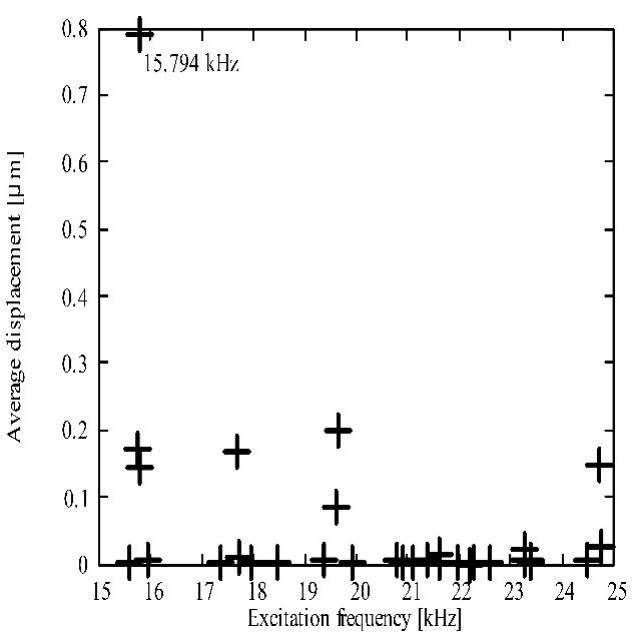

Fig. B3. Average displacement distribution based on excitation frequency ( $Y$ axis - stepped shaft)

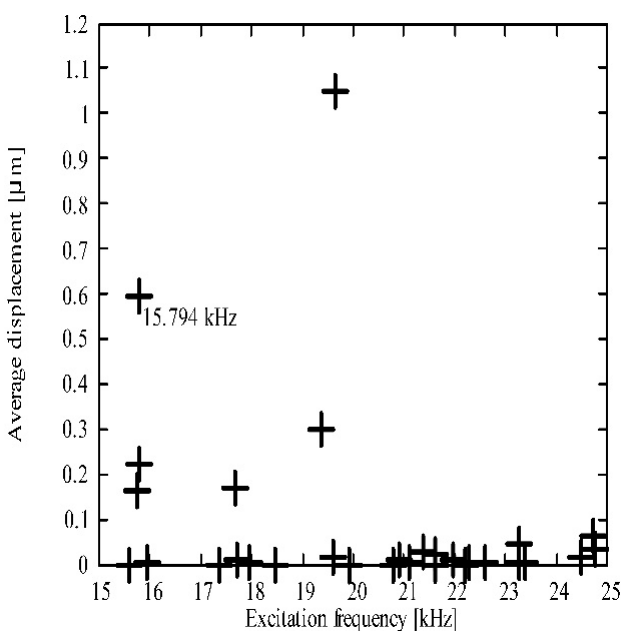

Fig. B4. Average displacement distribution based on excitation frequency ( $Z$ axis - stepped shaft)

\subsection{Appendix C}

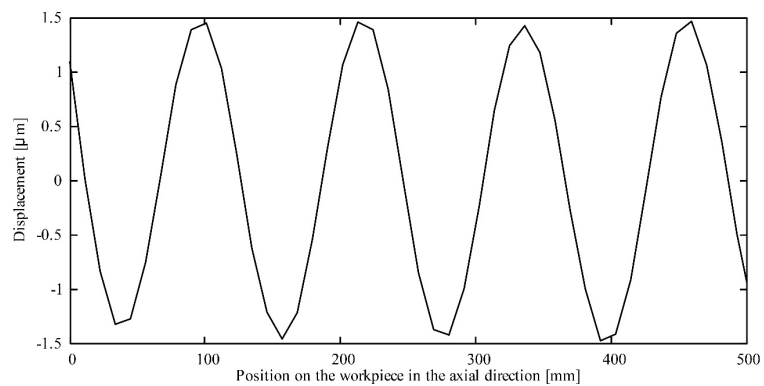

Fig. C1. Response of the uniform cylinder workpiece, driven by $2.1 \mathrm{~N}$ at $15.85 \mathrm{kHz}$ frequency

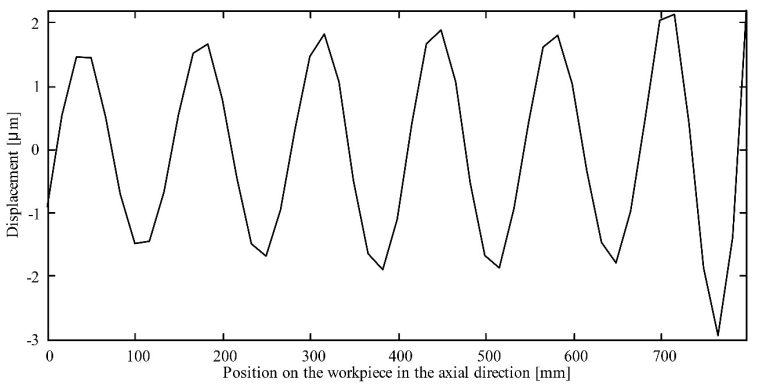

Fig. C2. Response of the stepped shaft workpiece, driven by $2.1 \mathrm{~N}$ at $15.794 \mathrm{kHz}$ frequency 